\title{
Characterization of p16 and E6 HPV-related proteins in uterine cervix high-grade lesions of patients treated by conization with large loop excision
}

\author{
MARIA TERESA RONCAGLIA ${ }^{1}$, JOSÉ HUMBERTO T.G. FREGNANI ${ }^{2}$, MARICY TACLA ${ }^{1}$, \\ SILVANA GISELE PEGORIN DE CAMPOS ${ }^{3}$, HÉLIO HEHL CAIAFFA ${ }^{4}$, ALEXANDRE AB'SABER ${ }^{5}$, \\ EDUARDO VIEIRA DA MOTTA ${ }^{1}$, VENÂNCIO AVANCINI FERREIRA ALVES ${ }^{5,6}$, \\ EDMUND C. BARACAT ${ }^{1}$ and ADHEMAR LONGATTO FILHO ${ }^{6-9}$
}

\begin{abstract}
${ }^{1}$ Department of Gynecology, Faculty of Medicine, São Paulo University, Cerqueira César; ${ }^{2}$ Center for Researcher Support, Barretos Cancer Hospital, Pio XII Foundation; ${ }^{3}$ Molecular Oncology Research Center, Barretos Cancer Hospital, Barretos; ${ }^{4}$ Laboratory of Medical Investigation (LIM) 03, Clinics Hospital Faculty of Medicine; ${ }^{5}$ Department of Pathology, Clinics Hospital; ${ }^{6}$ Laboratory of Medical Investigation (LIM) 14, Department of Pathology, Faculty of Medicine, São Paulo University, Cerqueira César, São Paulo, Brazil; ${ }^{7}$ Life and Health Sciences Research Institute (ICVS), School of Health Sciences, University of Minho, Campus de Gualtar, Braga; ${ }^{8} \mathrm{ICVS} / 3 \mathrm{~B}$ 's, PT Government Associate Laboratory, Guimarães, Braga, Portugal; ${ }^{9}$ Molecular Oncology Research Center, Barretos Cancer Hospital, Barretos, São Paulo, Brazil
\end{abstract}

Received January 18, 2013; Accepted April 25, 2013

DOI: 10.3892/ol.2013.1356

\begin{abstract}
Cervical cancer and its precursor lesions represent a significant public health problem for developing and less-developed countries. Cervical carcinogenesis is strongly correlated with persistent high-risk human papillomavirus (HPV) infection, which is mostly associated with expression of the p16 and E6 HPV-related proteins. The aim of this present study was to determine the expression of the p16 and E6 proteins in females with high-grade lesions treated with conization, and to discuss the role of these proteins as prognostic markers following treatment. In total, 114 females were treated for high-grade cervical intraepithelial neoplasia (CIN, grades 2/3) by conization with large loop excision of the transformation zone (LLETZ). Following surgery, the patients returned within 30-45 days for post-operative evaluation. A follow-up was conducted every 6 months for 2 years. At each follow-up appointment, a Pap smear, colposcopy and HPV DNA test were performed. E6 and p16 immunohistochemical tests were conducted on the surgical specimens. The positive expression of p16 was correlated with the presence of lesions
\end{abstract}

Correspondence to: Dr Adhemar Longatto-Filho, Laboratory of Medical Investigation (LIM) 14, Department of Pathology, Faculty of Medicine, São Paulo University, 455 Dr Arnaldo Avenue, Cerqueira César, São Paulo, Brazil

E-mail: longatto16@hotmail.com

Key words: human papillomavirus, high-grade squamous intraepithelial lesions, p16, conization with increased severity in the surgical specimens $(\mathrm{P}=0.0001)$. The expression of E6 did not demonstrate the same correlation $(\mathrm{P}=0.131)$. The HPV DNA hybrid, collected in the first post-operative consultation as a predictor of the cytological abnormalities identified at the 24-month follow-up assessment, presented a sensitivity of $55.6 \%$, a specificity of $84.8 \%$, a positive predictive value of $33.3 \%$ and a negative predictive value of $93.3 \%$. The role of p16INK4A as a marker of CIN was also demonstrated; the expression of p16 and E6, however, did not appear to be of any prognostic value in predicting the clearance of high-risk HPV following conization. A negative hybrid capture test was correlated with a disease-free outcome.

\section{Introduction}

Human papillomavirus (HPV) infects numerous females worldwide and is generally transmitted through sexual contact (1). The majority of HPV-induced lesions disappear 6-12 months after development, however, a small number progress to become high-grade squamous intraepithelial lesions (HSIL) and cervical cancer (2). The interaction of HPV with the host cells represents a significant cascade of molecular events that culminate in the natural history of cervical cancer development (3).

The high-risk HPV types encode two oncoproteins, E6 and E7. The E6 oncoprotein binds to the p53 tumor suppressor, resulting in its inactivation and the prevention of cellular apoptosis (4). The E7 oncoprotein binds to the retinoblastoma protein $(\mathrm{pRb})$ tumor suppressor, leading to continuous cell cycling without any repair check-points (5). In an attempt to prevent this continuous cell cycling, p16, a 
$\mathrm{pRb}$ regulator, is overexpressed and accumulates inside the cells (6). p16 is a protein that is expressed in low concentrations in healthy cells, but is overexpressed in cervical cancer and high-grade precursor lesions. Consequently, p16 overexpression is a significant marker of cervical lesions and is considered to be a useful test that may facilitate an improved diagnosis of severe cervical lesions (7). The HPV E6 oncoprotein is involved in a complementary pathway that is associated with cell cycle deregulation, where p53 is abrogated. The immunohistochemical expression of E6 has been proposed to be useful for determining a diagnosis and/ or prognosis (8). Finally, the hybrid capture 2 (HC2) test is a well-known molecular test that identifies a pool of high-risk HPVs. The test is used in combination with a liquid-based cytology examination to ascertain the HPV status in patients treated for HPV-induced lesions with undetermined cytology [atypical squamous cells of undetermined significance (ASC-US), atypical squamous cells, cannot exclude HSIL (ASC-H) or atypical glandular cell (AGC)], and in the primary screening of cervical lesions (9).

The aim of the present study was to characterize p16 expression in patients treated by conization with large loop excision, and to compare the p16 performance with the E6 immunohistochemical and $\mathrm{HC} 2$ test results in combination with the Pap smear examination.

\section{Patients and methods}

Patients. Between March 2006 and May 2009, 114 females were treated for high-grade cervical intraepithelial neoplasia (CIN 2/3) by conization with large loop excision of the transformation zone (LLETZ) at the Department of Gynecology, Faculty of Medicine, São Paulo University (Cerqueira César, Brazil). Following surgery, the patients returned within 30-45 days for post-operative evaluation. A follow-up was conducted every 6 months for 2 years. Each follow-up appointment comprised a Pap smear, colposcopy and HPV DNA test.

The procedure was explained to all the patient and written informed consent was provided. The study was approved by the ethics committee of the Clinics Hospital, Faculty of Medicine, São Paulo University. Immunohistochemical examinations, including E6 and p16 staining, were performed on the surgical specimens.

Hybrid capture assay. The $\mathrm{HC} 2$ test was conducted according to the manufacturer's instructions (Quiagen, Gaithersburg, MD, USA). Only high-risk HPVs were examined and the carcinogenic types included types $16,18,31,33,35,39,45,51$, $52,56,58,59$ and 68.

\section{Immunohistochemistry}

p16 CINTEC test. The immunohistochemical reaction for p16 was performed with the CINtec ${ }^{\circledR}$ Histology kit according to the manufacturer's instructions (Roche MTM Laboratories, Heidelberg, Germany). Briefly, subsequent to the use of retrieval solution at $125^{\circ} \mathrm{C}$ for $3 \mathrm{~min}$ and $90^{\circ} \mathrm{C}$ for $20 \mathrm{~min}$, the slides were cooled at room temperature and washed in wash buffer (1:10 dilution), for $5 \mathrm{~min}$. Endogenous peroxidase was blocked with peroxidase-blocking reagent at a volume of
$30 \mathrm{ml}$ per slide for $5 \mathrm{~min}$. Primary ready-to-use p16 antibody was added after $30 \mathrm{~min}$ at room temperature. Visualization reagent was utilized for signal amplification. The revelation with diaminobenzidine (DAB) was performed with $15 \mathrm{ml}$ 3,3'-diaminobenzidine (DAB) chromogen and counterstained with hematoxylin.

E6 immunohistochemistry. Antigen retrieval was conducted using a microwave and a solution of $10 \mathrm{mM}$ citric acid (pH 6.0; Merck KGaA, Darmstadt, Germany) for three minutes at $125^{\circ} \mathrm{C}$. Endogenous peroxidase blocking was performed with $6 \%$ hydrogen peroxide $\left(\mathrm{H}_{2} \mathrm{O}_{2}\right)$. The primary E6 monoclonal antibody (C1P5) sc460, from mouse E6 HPV 16 and HPV 18 (Santa Cruz Biotechnology, Inc., Santa Cruz, CA, USA) was used at a 1:200 dilution. The revelation was performed with an ADVANCE ${ }^{\mathrm{TM}}$ horseradish peroxidase (HRP) kit (Dako, Carpinteria, CA, USA).

Evaluation of the p16 and E6 immunostaining. The p16 reaction was evaluated as positive when nuclear or cytoplasmic immunostaining was clearly demonstrated. The scoring was conducted as previously demonstrated by Longatto-Filho et $a l$, with slight modifications (10): Negative (no reaction or $\leq 1 \%$ positive cells), sporadic ( $>1 \%$ but $\leq 25 \%$ positive cells), moderate $(>25 \%$ but $\leq 50 \%$ positive cells) and diffuse $(>50 \%$ positive cells).

Dichotomic negative/positive evaluation was adapted to determine E6 immunoreaction as suggested by Lin et al (8). Brown nuclear staining was considered as a positive reaction to E6 HPV 16/18 proteins.

Statistical analysis. The Fisher's exact test was performed to compare categorical variables. To calculate the parameters of the hybrid capture accuracy (sensitivity, specificity, positive predictive value and negative predictive value), the follow-up Pap smear was adopted as the gold standard. In all statistical tests, $\mathrm{P}<0.05$ was considered to indicate a statistically significant difference.

\section{Results}

The HC2 HPV DNA test (developed in 1997 by Digene Corporation, Gaithersburg, MD, USA) was performed in 112 of the included patients prior to the surgical procedure. A total of 108 patients tested positive for HPV DNA and four tested negative prior to the procedure. Two cases had no HC2 HPV DNA test performed. Table I presents a description of the population involved in the study.

The cytological results prior to the surgical procedure were as follows: 71 patients presented with HSIL, 2 with HSIL and AGC and 14 with low-grade squamous intraepithelial lesions (LSIL). Another 6 patients exhibited ASC-H, 1 exhibited ASC-H + AGC, and 6 exhibited ASC-US. Only 1 patient presented with ASC-US + AGC, 4 presented with AGC and 9 were classified as having normal cytology. The patients who had normal, ASC-US or LSIL cytology presented with CIN $2 / 3$ in their biopsy samples. The cytological and histological findings prior to treatment are listed in Table II.

The pathological examination of the excised cervical specimens revealed the following diagnoses: 18 (15.8\%) patients with chronic cervicitis; $11(9.6 \%)$ with CIN 1; 19 (16.7\%) with CIN 2; 64 (56.1\%) CIN 3; one (0.9\%) with CIN 3 and adeno- 
Table I. Population description data.

\begin{tabular}{lc}
\hline Characteristic & Value \\
\hline Age (years) & \\
Range & $20-57$ \\
Mean (SD) & $33.89(8.593)$ \\
Age at first sexual intercourse (years) & $9-29$ \\
Range & $16.5(2.836)$ \\
Mean (SD) & \\
Number of sexual partners & $1-40$ \\
Range & $4.07(5.221)$ \\
Mean (SD) & $0-7$ \\
Number of births & $2.29(1.538)$ \\
Range & \\
Mean (SD) & $76(66.7)$ \\
Smoking status, n (\%) & \\
Non-smoker & $37(32.5)$ \\
Smoker & \\
Birth control methods, $\mathrm{n}(\%)^{\mathrm{b}}$ & $32(28.1)$ \\
None & $42(36.8)$ \\
Hormonal & $38(33.3)$ \\
Others (IUD, tubal ligation, condom) & \\
\hline
\end{tabular}

${ }^{\mathrm{a}}$ There was no data on the smoking status of 1 patient. ${ }^{\mathrm{b}}$ There was no data on the birth control method for 2 patients. IUD, intrauterine device.

Table II. Cytological and histological findings prior to surgery.

Tumor characteristic

No. of patients $(\%)$

$\begin{array}{lc}\text { Cytology } & \\ \text { Low-grade } & 29(25.4) \\ \text { High-grade } & 85(74.6) \\ \text { Histology } & \\ \text { Low-grade } & 15(13.2) \\ \text { High-grade } & 93(81.6) \\ \text { Non-realized } & 6(5.3)\end{array}$

carcinoma in situ (AIS), and one (0.9\%) with micro-invasive carcinoma. Table III shows the results of the HC2 HPV DNA tests performed prior to the surgical procedure, and those of the E6 and p16 immunohistochemical tests on the tissue samples of the surgical specimens. The correlation between the expression of the E6 and p16 proteins in the surgical specimen is shown in Table IV. As predicted, the negative expression of p16 was significantly correlated with the negative expression of the E6 oncoprotein. In addition, the positive expression of p16 was significantly correlated with the positive expression of the E6 oncoprotein.

The results of the p16 and E6 immunohistochemical reactions, the HC2 HPV DNA tests prior to the surgical procedure

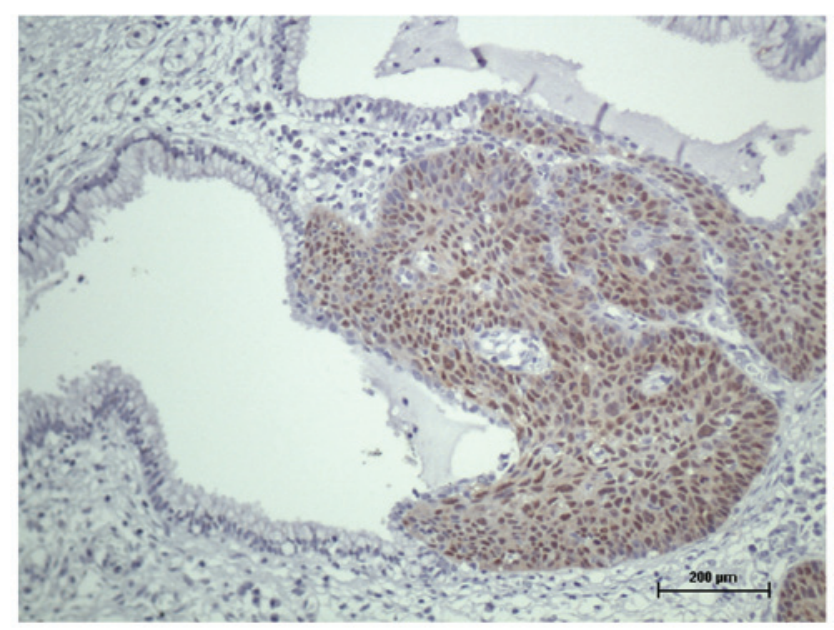

Figure 1. High-grade intraepithelial lesion exhibiting a strongly-positive immunohistochemical reaction for p16 (magnification, $\mathrm{x} 20$ ).

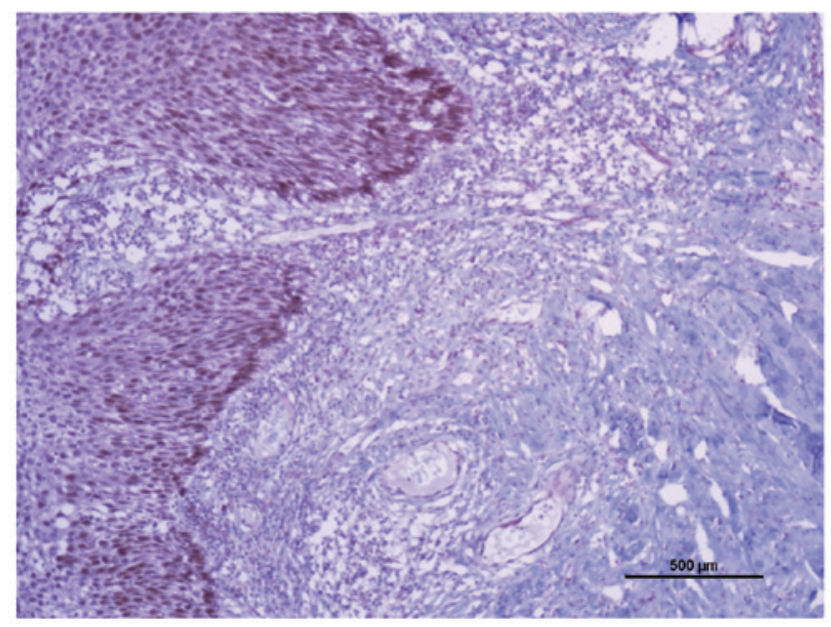

Figure 2. High-grade intraepithelial lesion exhibiting a strongly-positive nuclear immunohistochemical reaction for E6 (magnification, x20).

and the histopathological findings in the surgical specimens are presented in Table V. The positive expression of p16 was correlated with lesions of increased severity identified in the surgical specimen ( $\mathrm{P}=0.0001$; Fig. 1), however, no such correlation was identified with E6 expression ( $\mathrm{P}=0.131$; Fig 2).

Table VI presents the comparison between the cytological diagnoses prior to surgery and the HPV-related markers; p16, E6 and $\mathrm{HC} 2$ status.

The accuracy values of the HC2 test in predicting cytological abnormalities over the 2-year follow-up are shown in Table VII. The HC2 test was results were compared with the cytology. The tests were conducted simultaneously during the follow-up period.

According to the results of the HPV DNA hybrid, collected in the first post-operative follow-up as a predictor of the cytological abnormalities found in the 24-month follow-up period, a sensitivity of $55.6 \%$, a specificity of $84.8 \%$, a positive predictive value of $33.3 \%$ and a negative predictive value of 93.3\% were recorded. In comparison, Table VII describes the accuracy of the HC2 test in predicting cytological abnormali- 
Table III. HC2 HPV DNA test prior to the surgical procedure, and the subsequent E6 and p16 immunohistochemical test data.

\begin{tabular}{lcccc}
\hline Test & Positive, $\mathrm{n}(\%)$ & Negative, $(\%)$ & Not performed, $(\%)$ & Total, $\mathrm{n}(\%)$ \\
\hline HC2 & $108(94.7)$ & $4(3.5)$ & $2(1.8)$ & $114(100.0)$ \\
E6 & $45(39.5)$ & $69(60.5)$ & - & $114(100.0)$ \\
p16 & $74(64.9)$ & $40(35.1)$ & - & $114(100.0)$
\end{tabular}

HC2, hybrid caputure 2; HPV, human papillomavirus.

Table IV. Correlation between p16 and E6 protein immunohistochemical expression.

\begin{tabular}{|c|c|c|c|}
\hline & \multicolumn{2}{|c|}{ E6, n (\%) } & \multirow[b]{2}{*}{ Total, n (\%) } \\
\hline & Negative & Positive & \\
\hline \multicolumn{4}{|l|}{ p16 } \\
\hline Negative & $30(75.0)$ & $10(25.0)$ & $40(100.0)$ \\
\hline Positive & $39(52.7)$ & $35(47.3)$ & $74(100.0)$ \\
\hline Total & $69(60.5)$ & $45(39.5)$ & $114(100.0)$ \\
\hline
\end{tabular}

$\mathrm{P}=0.027$.

Table V. Correlation between p16 and E6 expression and HC2 status, and the histopathological findings in the surgical specimen.

A, p16

$\begin{array}{llll}\text { Negative, } \mathrm{n}(\%) & \text { Positive, } \mathrm{n}(\%) & \text { Total, } \mathrm{n}(\%) & \text { P-value }\end{array}$

Histopathological diagnosis

\begin{tabular}{llrr} 
Cervicitis/CIN 1 & $23(79.3)$ & $6(20.7)$ & $29(100.0)$ \\
CIN 2/CIN 3/AIS/Ca microinvasor & $17(20.0)$ & $68(80.0)$ & $85(100.0)$ \\
Total & $40(35.1)$ & $74(64.9)$ & $114(100.0)$ \\
\hline
\end{tabular}

$\mathrm{B}, \mathrm{E} 6$

\begin{tabular}{llll} 
Negative, n $(\%)$ & Positive, n $(\%)$ & Total, $n(\%)$ & P-value \\
\hline
\end{tabular}

Histopathological diagnosis

Cervicitis/CIN 1

CIN 2/CIN 3/AIS/Ca microinvasor

Total

C, DNA HPV test

$\begin{array}{lrr}21(72.4) & 8(27.6) & 29(100.0) \\ 48(56.5) & 37(43.5) & 85(100.0) \\ 69(60.5) & 45(39.5) & 114(100.0)\end{array}$

$21(72.4)$

$69(60.5)$

\begin{tabular}{|c|c|c|c|c|}
\hline & Negative, n (\%) & Positive, $\mathrm{n}(\%)$ & Total, n (\%) & P-value \\
\hline \multicolumn{5}{|l|}{ Histopathological diagnosis } \\
\hline Cervicitis/CIN 1 & $4(14.8)$ & $23(85.2)$ & $27(100.0)$ & \\
\hline CIN 2/CIN 3/AIS/Ca microinvasor & $0(0.0)$ & $85(100.0)$ & $85(100.0)$ & \\
\hline Total & $4(3.6)$ & $108(96.4)$ & $112(100.0)^{\mathrm{a}}$ & 0.0001 \\
\hline
\end{tabular}

* Two patients did not undergo the DNA HPV test prior to the surgical procedure. CIN, cervical intraepithelial neoplasia; HC2, hybrid capture 2; HPV, human papillomavirus; AIS, in situ adenocarcinoma; Ca, squamous cell carcinoma. 
Table VI. Comparison among the cytological diagnoses prior to surgery and the HPV related-markers, p16, E6 and HC2.

\begin{tabular}{|c|c|c|c|c|c|c|c|}
\hline \multirow[b]{3}{*}{ Cytological diagnosis } & \multicolumn{7}{|c|}{ HPV-related markers (n) } \\
\hline & \multicolumn{2}{|c|}{ p16 } & \multicolumn{2}{|c|}{ E6 } & \multicolumn{2}{|c|}{$\mathrm{HC} 2$} & \multirow[b]{2}{*}{ Total } \\
\hline & Positive & Negative & Positive & Negative & Positive & Negative & \\
\hline Negative & 5 & 4 & 6 & 3 & 9 & 0 & 9 \\
\hline ASC-US & 3 & 3 & 2 & 4 & 5 & 1 & 6 \\
\hline ASC-US+AGC & 0 & 1 & 0 & 1 & 1 & 0 & 1 \\
\hline ASC-H & 4 & 2 & 4 & 2 & 6 & 0 & 6 \\
\hline $\mathrm{ASC}-\mathrm{H}+\mathrm{AGC}$ & 1 & 0 & 1 & 0 & 1 & 0 & 1 \\
\hline LSIL & 9 & 5 & 6 & 8 & 14 & 0 & 14 \\
\hline HSIL & 48 & 23 & 24 & 47 & 66 & 3 & $71^{\mathrm{a}}$ \\
\hline HSIL+AGC & 1 & 1 & 0 & 2 & 2 & 0 & 2 \\
\hline AGC & 3 & 1 & 2 & 2 & 4 & 0 & 4 \\
\hline \multirow[t]{2}{*}{ Total } & 74 & 40 & 45 & 69 & 108 & 4 & \\
\hline & \multicolumn{2}{|c|}{114} & \multicolumn{2}{|c|}{114} & \multicolumn{2}{|c|}{$112^{\mathrm{a}}$} & \\
\hline
\end{tabular}

${ }^{a}$ Two patients did not undergo the HC2 test performed prior to the surgical procedure. HPV, human papillomavirus; HC2, hybrid capture 2; ASC-US, atypical squamous cell of undetermined significance; AGC, atypical grandular cell; ASC-H, atypical squamous cells, cannot excluse HSIL; LSIL low grade squamous intraepithelial lesion; HSIL, high grade squamous intraepithelial lesion.

Table VII. The accuracy values of the HC2 test in predicting cytological abnormalities over a 2-year follow-up period.

\begin{tabular}{|c|c|c|c|c|c|}
\hline Time (months) & $\begin{array}{c}\text { Positive predictive } \\
\text { value }(\%)\end{array}$ & $\begin{array}{c}\text { Negative predictive } \\
\text { value }(\%)\end{array}$ & $\begin{array}{c}\text { Sensitivity } \\
(\%)\end{array}$ & $\begin{array}{l}\text { Specificity } \\
(\%)\end{array}$ & $\begin{array}{c}\text { Total no. of } \\
\text { patients }\end{array}$ \\
\hline 6 & 50.0 & 97.3 & 83.3 & 87.8 & 94.0 \\
\hline 12 & 42.9 & 96.4 & 75.0 & 87.1 & 70.0 \\
\hline 18 & 33.3 & 100.0 & 100.0 & 86.0 & 61.0 \\
\hline 24 & 54.5 & 98.0 & 85.7 & 90.7 & 61.0 \\
\hline
\end{tabular}

HC2, hybrid capture 2 .

ties at each follow-up examination performed over a 2-year period.

\section{Discussion}

In our previous study, containing partial information from the present study, we identified that patients with a combination of negative cytology and negative hybrid capture test results did not exhibit high-grade lesions at the conization follow-up examination (11). The results of the present study supported the use of the HC2 HPV DNA test, collected in the first post-operative assessment, as a marker of disease recurrence or a disease-free status (11). Additionally, the results demonstrated that the characterization of p16 in a well-controlled population that underwent cervix conization due to the HSIL alteration was concordant with previous results. This indicated that the p16 marker was strongly expressed in high-grade lesions, and that it had the potential to identify severe lesions when associated with a positive hybrid capture test (12). Furthermore, p16 was expressed in
$80 \%$ of CIN $2^{+}$biopsy-diagnosed cases, which reinforced its potential use as an accurate marker of high-grade cervical lesions.

p16 changes in the methylation profile of cervical HPV-induced lesions have been implicated in transcription and replication control, potentially triggering the neoplastic transformation (13). This is a noteworthy finding, as different HPV methylomes are linked to the various stages of squamous intraepithelial lesion differentiation, including those of a high-grade phenotype. However, the enhanced expression of the viral E6 oncogene in advanced lesions of persistent HPV infections was not observed in our specimens as we had predicted (13). The immunohistochemical expression of the E6 oncoprotein has been recorded in different types of tumors, presumably induced by persistent high-risk HPV infection; however, the frequency of a positive immunoreaction was low (14-17). For the E6 immunohistochemical evaluation in cervical HPV-induced lesions, we did not identify any studies comparable with the present study; however, the negative p16 and E6 reactions were observed in combination in $75 \%$ of 
cases, but only $52.7 \%$ of positive reactions were identified in combination. This may be due to a limitation in sensitivity for the immunohistochemical reaction, as 37 of the CIN $2^{+}$cases $(43.5 \%)$ were E6-positive. It has been suggested that differences in E6 variants prevalent in cervical carcinoma are not correlated with the carcinogenic potential of the E6 protein. Moreover, E6 variants have revealed comparable abilities in preventing growth arrest and inhibiting the induced p53 elevation. Differences were detected in the ability to deregulate stratification and differentiation, as well as in modulating apoptosis and hyperactivating the Wnt signaling cascade (18). The absence of a correlation between p16 and E6 expression was not predicted, however, the reason for this discrepancy may be attributed to the low sensitivity of E6 immunohistochemical expression (15).

The present study demonstrated the predictive potential of the negative values in the hybrid capture test during the follow-up of the patients that underwent conization. In addition, specificity was observed in each clinical visit. Repeated detection of high-risk HPV was demonstrated to be significantly more specific, but less sensitive, in identifying females at risk for CIN $2 / 3$ as compared with a single time-point measurement. Moreover, sensitivity has been estimated to decrease and specificity to increase when the testing intervals were increased from 12 to 24 months (19). The variations in sensitivity and specificity, observed in the present study during the 24-month visit following conization, did not demonstrate such significant disparity.

In conclusion, the current study supported the critical function of p16INK4A as a highly specific marker of CIN. However, the immunohistochemical expression of p16 has been previously demonstrated to have no prognostic value in predicting the clearance of high-risk HPV following conization (20). Overexpression of p16 in human tumors as a whole has been demonstrated to be correlated with high-grade pre-malignant lesions, high-grade tumors and senescence (21).

\section{References}

1. zur Hausen H: Papillomaviruses causing cancer: evasion from host-cell control in early events in carcinogenesis. J Natl Cancer Inst 92: 690-698, 2000.

2. zur Hausen H: Papillomaviruses and cancer: from basic studies to clinical application. Nat Rev Cancer 2: 342-350, 2002.

3. Schiffman M, Castle PE, Jeronimo J, Rodriguez AC and Wacholder S: Human papillomavirus and cervical cancer. Lancet 70: 890-907, 2007.

4. Tungteakkhun SS and Duerksen-Hughes PJ: Cellular binding partners of the human papillomavirus E6 protein. Arch Virol 153: 397-408, 2008.

5. Doorbar J: The papillomavirus life cycle. J Clin Virol 32 (Suppl 1): S7-S15, 2005.

6. Cuschieri K and Wentzensen N: Human papillomavirus mRNA and p16 detection as biomarkers for the improved diagnosis of cervical neoplasia. Cancer Epidemiol Biomarkers Prev 17: 2536-2545, 2008.
7. Carozzi F, Confortini M, Dalla Palma P, Del Mistro A, Gillio-Tos A, De Marco L, et al: Use of p16-INK4A overexpression to increase the specificity of human papillomavirus testing: a nested substudy of the NTCC randomised controlled trial. Lancet Oncol 9: 937-945, 2008.

8. Lin HP, Wang YP and Chiang CP: Expression of p53, MDM2, p21, heat shock protein 70, and HPV 16/18 E6 proteins in oral verrucous carcinoma and oral verrucous hyperplasia. Head Neck 33: 334-340, 2011

9. Schiffman M, Wentzensen N, Wacholder S, Kinney W, Gage JC and Castle PE: Human papillomavirus testing in the prevention of cervical cancer. J Natl Cancer Inst 103: 368-383, 2011.

10. Longatto-Filho A, Etlinger D, Pereira SM, Kanamura CT, di Loreto C, Santos Gda C, et al: The association of p16(INK4A) and fragile histidine triad gene expression and cervical lesions. J Low Genit Tract Dis 11: 151-157, 2007.

11. Roncaglia MT, Tacla M, Vieira da Motta E, Caiaffa H, Ab'Saber A, Alves VA, Longatto Filho A and Baracat EC: Evaluation of the combination of cytology and hybrid capture to safely predict the high-grade lesion status of patients treated with conization with large loop excision of the transformation zone. Acta Cytol 55: 421-425, 2011.

12. Reuschenbach M,Clad A, von Knebel DoeberitzC, Wentzensen N, Rahmsdorf J, Schaffrath F, Griesser H, Freudenberg N and von Knebel Doeberitz M: Performance of p16INK4a-cytology, HPV mRNA, and HPV DNA testing to identify high grade cervical dysplasia in women with abnormal screening results. Gynecol Oncol 119: 98-105, 2010.

13. Vinokurova $S$ and von Knebel Doeberitz M: Differential methylation of the HPV 16 upstream regulatory region during epithelial differentiation and neoplastic transformation. PLoS One 6: e24451, 2011.

14. Wu QJ, Guo M, Lu ZM, Li T, Qiao HZ and Ke Y: Detection of human papillomavirus-16 in ovarian malignancy. Br J Cancer 89: 672-675, 2003

15. Qi ZL, Huo X, Xu XJ, Zhang B, Du MG, Yang HW, Zheng LK, Li J and Shen ZY: Relationship between HPV16/18 E6 and 53, 21WAF1, MDM2, Ki67 and cyclin D1 expression in esophageal squamous cell carcinoma: comparative study by using tissue microarray technology. Exp Oncol 28: 235-240, 2006.

16. Lawson JS, Glenn WK, Heng B, Ye Y, Tran B, Lutze-Mann L and Whitaker NJ: Koilocytes indicate a role for human papilloma virus in breast cancer. Br J Cancer 101: 1351-1356, 2009.

17. Akil N, Yasmeen A, Kassab A, Ghabreau L, Darnel AD and Al Moustafa AE: High-risk human papillomavirus infections in breast cancer in Syrian women and their association with Id-1 expression: a tissue microarray study. Br J Cancer 99: 404-407, 2008.

18. Zehbe I, Lichtig H, Westerback A, Lambert PF, Tommasino M and Sherman L: Rare human papillomavirus 16 E6 variants reveal significant oncogenic potential. Mol Cancer 10: 77, 2011.

19. Marks M, Castle PE, Schiffman M and Gravitt PE: Evaluation of any or type-specific persistence of high-risk human papillomavirus for detecting cervical precancer. J Clin Microbiol 50: 300-306, 2012.

20. Branca M, Ciotti M, Santini D, Di Bonito L, Giorgi C, Benedetto A, Paba P, Favalli C, Costa S, Agarossi A, Alderisio M and Syrjänen $\mathrm{K}$ : p16(INK4A) expression is related to grade of cin and high-risk human papillomavirus but does not predict virus clearance after conization or disease outcome. Int J Gynecol Pathol 23: 354-365, 2004.

21. Romagosa C, Simonetti S,López-Vicente L, Mazo A, Lleonart ME, Castellvi J and Ramon y Cajal S: p16(Ink4a) overexpression in cancer: a tumor suppressor gene associated with senescence and high-grade tumors. Oncogene 30: 2087-2097, 2011. 